\title{
Multiple sclerosis in the Cambridge health district of East Anglia
}

\author{
C J Mumford, M B Fraser, N W Wood, D A S Compston
}

\begin{abstract}
A survey of multiple sclerosis (MS) in the Cambridge Health District has identified 374 cases in a population of 288 410, giving a prevalence of 130 per 100000 . A total of 322 cases $(86 \%)$ had either clinically definite or probable multiple sclerosis on 1 July 1990 (112 per 100 000) and 52 cases (14\%) had suspected multiple sclerosis (18 per 100 000.) The incidence during 1989-91 was 5.94 per 100000 per year. The prevalence figure is higher than in recent surveys from other southern parts of the United Kingdom, but correction for the age and sex characteristics of the at risk population eliminates these differences. The overall prevalence of multiple sclerosis is probably between 108 and 120 per 100000 in the southern United Kingdom.
\end{abstract}

(F Neurology Neurosurg Psychiatry 1992;55:877-882)

Most epidemiological statistics for multiple sclerosis in the British Isles are derived from surveys performed in the north of England or in Scotland, and the majority of these studies were carried out more than ten years ago. ${ }^{1-3}$ There have been only three recent populationbased surveys of the prevalence of multiple sclerosis (MS) in the southern part of the United Kingdom, ${ }^{4-6}$ and a small general practice based study has also been reported. ${ }^{7}$ These surveys are useful for determining health service requirements but sporadic and infrequent studies do not resolve issues such as the nature of factors which determine the geographical distribution of the disease.

Improved diagnostic methods, increased awareness of the disease and progress in information technology mean that the results of earlier epidemiological studies are not readily comparable with the more recent surveys. A steady increase in disease frequency has been demonstrated in those parts of the UK which have been repeatedly scrutinised, such as the northeast of Scotland, ${ }^{389}$ but it is unclear whether this indicates a change in incidence, or merely reflects improved case identification and ascertainment.

There is therefore a need for contemporary information on the epidemiology of multiple sclerosis in the UK, with contributions from all parts of Britain, especially the heavily populated southern regions. There have been no epidemiological surveys of MS in East Anglia, despite the existence over many years of a comprehensive clinical neurological service, and this study provides the first prevalence figure for this part of the southern UK.

\section{Study Area}

The county of Cambridgeshire in England lies between latitudes $52^{\circ} 00^{\prime}$ and $52^{\circ} 45^{\prime}$ north, and longitudes $0^{\circ} 30^{\prime}$ west and $0^{\circ} 30^{\prime}$ east, being almost bisected by the Greenwich meridian. The county occupies 340910 hectares. Responsibility for medical care rests with four health authorities, the largest of which is the Cambridge Health Authority covering an area of 159935 hectares in the south and east of the county. The area of the Cambridge Health Authority corresponds almost exactly to the boundaries of the predominantly rural administrative districts of South and East Cambridgeshire, as well as the university city of Cambridge. Six parishes in the extreme western part of South Cambridgeshire are incorporated in the neighbouring Huntingdon Health Authority. The three administrative districts of South Cambridgeshire, East Cambridgeshire and the City of Cambridge were chosen as the survey area for this study, including the six parishes not strictly falling within the area of the Cambridge Health Authority. Accurate population figures for this area are maintained by the Cambridgeshire County Council Population Research Group, ${ }^{10}$ and the mid-year estimate for 1990 was 288410 , representing an increase of $5.6 \%$ over the figure obtained during the 1981 census. ${ }^{11}$

Four clinical neurologists based at the regional neurosciences centre in Cambridge are responsible for providing services in the study area and surrounding parts of East Anglia. The neurology unit in Cambridge has departmental records for all patients seen since the mid 1960s, irrespective of domicile. The study area is served by 158 general practitioners; a number of patients living near the boundary, particularly around Newmarket in Suffolk and Royston in Hertfordshire, are registered with general practitioners based in adjoining counties.

\section{Methods}

Two of the authors (CJM \& NWW) scrutinised more than 27000 neurological records held in the neurology department at Addenbrooke's Hospital which enabled a list to be made of all patients seen by Cambridge-based neurologists in whom a diagnosis of MS had been considered or confirmed since 1965. This list was compared with entries on the Cambridge- 
shire Family Health Services Authority computer, allowing patients with suspected or confirmed MS who had been seen by the neurology department, were still alive and currently resident in the study area to be identified.

Four other sources of patients with MS were used. First, the nature of the study was explained to general practitioners and they were asked to provide names and contact addresses for all patients registered with their practice in whom the diagnosis of multiple sclerosis was suspected or had been confirmed, even if the patient was unaware of the diagnosis, or thought to be unwilling to participate in the study. A second letter was sent to practices which did not reply within two months. Letters were also sent to practices outside the study area, where there was a likelihood that registered patients lived in the study area. Secondly all local branches of the Multiple Sclerosis Society were asked to provide their membership list. Thirdly, a letter was sent to all nursing homes and facilities for disabled persons in the county seeking to identify patients with multiple sclerosis, and to provide the names of the general practitioners of those patients' so that further contact could be made. Finally, the recently installed computerised patient database which is in operation at Addenbrooke's Hospital was used to provide a list of patients with multiple sclerosis who had been seen during the previous year. In this way a provisional register was made of prevalent suspected, probable or definite cases of multiple sclerosis, who were known to be resident in the area under study.

With the consent of the patient's general practitioner, attempts were then made to contact all those on the register and the patient was interviewed and examined at home to confirm or refute the diagnosis; where this was not possible, patients' hospital and/or general practice records were inspected. For those cases on the provisional register who had been examined by a local neurologist in the six months before prevalence day, the diagnostic assessment of that clinician was accepted without additional information, although residence in the study area was confirmed. Prevalent patients were classified using the diagnostic criteria of Poser et al. ${ }^{12}$ Clinically definite and laboratory supported definite cases were collectively assigned a status of "definite MS", clinically probable and laboratory supported probable cases were combined as "probable multiple sclerosis". Other cases were classified as "suspected MS" or "not MS", as appropriate. To allow comparison with other published data, prevalent patients were also classified according to Allison and Millar's method. ${ }^{13}$

Patients on the provisional register who had recently died or moved from the study area before prevalence day were excluded as were a few registered patients who proved to be untraceable. Age and sex specific prevalence rates were determined and, in line with other recent prevalence studies, ${ }^{56}$ a standardised prevalence ratio was calculated using the 1961 survey of Northern Ireland as the denominator. ${ }^{14}$ All new cases of MS seen by any of the Cambridge-based neurologists were recorded prospectively from July 1990 giving a crude estimate of annual incidence for MS. The study was approved by the Ethical Committee of the Cambridge Health Authority and conformed with the requirements of the Data Protection Act.

\section{Results}

A total of 27974 departmental records were examined, and this produced 1545 cases of confirmed or suspected MS. Because many of the records were not current and related to a population spread over a wide geographical area, the majority of cases $(968,63 \%)$ had never lived in Cambridgeshire, had moved away, or were deceased. Five hundred and seventy seven $(37 \%)$ patients were alive, but 234/577 (41\%) lived outside the study area: $343 / 577$ (59\%) patients identified from this source were therefore alive, registered with a general practitioner in the county and known to be resident in the area of the Cambridge Health Authority on prevalence day. These 343 names formed the basis of the provisional register.

Replies to the survey of general practitioners achieved a response rate of $94 \%$, responses being sent by, or on behalf of, 149 of the 158 general practitioners who were contacted. All practices located outside the study area replied. 239 names were identified from this source, of whom $224 / 239$ (94\%) were notified by practitioners in the study area and 15/239 (6\%) by practitioners based in neighbouring counties. Three of these names had been diagnosed at neurological centres other than Cambridge. One hundred and forty five names of patients in the study area were obtained from local multiple sclerosis societies-126 from the Cambridge branch and 19 from Newmarket. No member of other local branches (Huntingdon and Peterborough) was resident in the study area. The survey of nursing homes and other facilities for the disabled produced only 9 names. Data from the Addenbrooke's Hospital computer identified 42 patients who had been an in patient at the hospital with a diagnosis of suspected or confirmed multiple sclerosis since 1 August 1989 , all of these had also been identified from departmental records.

Combination of names obtained using these five sources gave a provisional register of 477 names. Unlike the provisional register employed in previous comparable surveys, ${ }^{5}$ names of patients obtained from the departmental records had already been scrutinised to confirm that they were alive and resident in the study area, before they were entered on the provisional list.

All information on the provisional register was reassessed and $28 / 477$ patients $(6 \%)$ were found to have been included in error since they were either resident outside the study area (9/477), known to have moved $(15 / 477)$ or died (4/477). Three of the 477 names (1\%) 
had been included twice on the provisional register, once as a result of a difference in spelling the patient's surname in records kept at hospital and by the general practitioner, and in two cases due to different first names being used in hospital and general practice notes. Six of the 477 names $(1 \%)$ proved to be untraceable and were excluded from the survey. In $49 / 477(10 \%)$ cases MS had been included in a list of differential diagnoses, and an alternative diagnosis had since been established, or a firm diagnosis of multiple sclerosis had been replaced by another diagnosis. The provisional register of 477 names was therefore reduced to 391.

A total of $125 / 391$ (32\%) patients had been seen by a local neurologist in the six months before prevalence day. In $83(66 \%)$ of these "currently attending" cases, the diagnostic classification assigned was based on recent information in the case notes. In 42 cases (34\%) diagnostic classification was made on the basis of personal interview and examination, supplemented by information in the case notes. Classification was made on the basis of personal interview in the patient's home in $\mathbf{1 2 8}$ $(48 \%)$ of the remaining 266 cases, by telephone interview $(2(0.8 \%))$, or examination of departmental and/or general practitioner records $(136 / 266(60 \%))$ cases; the latter group included 21 cases in whom permission to contact the patient had not been granted by the general practitioner.

Two hundred and fifty five of the 391 cases $(65 \%)$ were therefore classified as a result of direct personal contact, either in the patient's home, by telephone, or as a result of recent contact with a local consultant neurologist and $136 / 391$ cases (35\%) were classified from hospital and/or general practice records. Using this information the diagnosis of multiple sclerosis was rejected in $17 / 391(4 \%)$ cases, usually because personal contact or hospital records showed that another diagnosis had been established. Therefore, on prevalence day, $374 / 391$ patients (96\%) had definite, probable or suspected MS (table 1).

The prevalence of MS in the Cambridge Health Authority on 1 July 1990 was $374 / 288,410\left(130 / 10^{5}\right)$ of whom $322(86 \%$ or
Table 1 Sources of identification of prevalent MS patients in the Cambridge Health Authority

\begin{tabular}{lcl}
\hline Source & No (\%) & $\begin{array}{l}\text { Sole means of } \\
\text { identification }\end{array}$ \\
\hline $\begin{array}{l}\text { Departmental records } \\
\text { General practitioners }\end{array}$ & $290(78)$ & $98(26)$ \\
$\begin{array}{l}\text { Multiple Sclerosis Society } \\
\text { branches }\end{array}$ & $145(39)$ & $40(11)$ \\
$\begin{array}{l}\text { Hospital patient database } \\
\text { Local nursing homes }\end{array}$ & $42(11)$ & 0 \\
Total prevalent cases & $9(2)$ & $1(0.3)$ \\
\hline
\end{tabular}

$\left.112 / 10^{5}\right)$ had definite or probable disease and $52\left(14 \%\right.$ or $\left.18 / 10^{5}\right)$ had suspected MS. Table 2 shows the breakdown of prevalent patients by diagnostic category, using the diagnostic criteria of Poser et al ${ }^{12}$ and of Allison and Millar. ${ }^{13}$ The prevalence of "probable MS" and "possible MS" was $107 / 10^{5}$ and $23 / 10^{5}$ respectively according to the criteria of Allison and Millar. Table 3 compares the prevalence rates for multiple sclerosis (using the Poser criteria) in the present study with the results of recent surveys from South East Wales ${ }^{5}$ and Southampton/South West Hampshire. ${ }^{6}$

Prevalence of MS per 100000 in the Cambridge Health Authority by age and sex is shown in table 4 and figure 1 . The sex ratio was 2.5 females to males. The age range of prevalent cases was $17-83$ years with a mean (SD) of $49.2(13.4)$ years. A total of $94 / 374$ patients (25\%) were over the age of $60,62 / 374(17 \%)$ over 65 and $12 / 374(3 \%) 75$ years or over. The mean age of patients at the time of diagnosis was 36.3 years (range 13-65 years) though mean age of onset of symptoms was estimated at 29.6 years (range $11-56$ years) and duration of disease from onset to prevalence day was 19.2 years. An estimate of the mean duration of illness from onset to death may be made by doubling the figure for the mean duration of the illness at prevalence day, ${ }^{5}$ and this gives a result for our study cohort of 38.4 years, but this means of assessing life expectancy has been criticised as an over-estimation. ${ }^{615}$

A summary of the present findings, and comparison with corresponding data from previous population based surveys in the UK is given in table 5, showing a standardised

Table 2 Prevalence of Multiple Sclerosis in the Cambridge Health Authority by Diagnostic Category

\begin{tabular}{|c|c|c|c|c|}
\hline Category & Number & $(\%)$ & $\begin{array}{l}\text { Prevalence } \\
\left(110^{5}\right)\end{array}$ & $\begin{array}{l}95 \% \text { confidence } \\
\text { intervals }\end{array}$ \\
\hline \multicolumn{5}{|l|}{ Poser et al ${ }^{12}$} \\
\hline CDMS & 256 & $68 \cdot 4$ & $88 \cdot 8$ & $(78-100)$ \\
\hline LSDMS & 10 & $2 \cdot 7$ & 3.5 & $(1-6)$ \\
\hline CPMS & 51 & $13 \cdot 6$ & $17 \cdot 7$ & $(13-23)$ \\
\hline LSPMS & i & 0.3 & 0.3 & $(0-1)$ \\
\hline MS? classification & 4 & $1 \cdot 1$ & $1 \cdot 4$ & $(0-3)$ \\
\hline Suspected & 52 & 13.9 & $18 \cdot 0$ & $(13-23)$ \\
\hline Total & 374 & $100 \cdot 0$ & $129 \cdot 7$ & $(117-143)$ \\
\hline \multicolumn{5}{|l|}{ Allison and Millar ${ }^{13}$} \\
\hline $\begin{array}{l}\text { Probable } \\
\text { Possible }\end{array}$ & $\begin{array}{r}309 \\
65\end{array}$ & $\begin{array}{l}82 \cdot 6 \\
17 \cdot 4\end{array}$ & $\begin{array}{r}107 \cdot 2 \\
22 \cdot 5\end{array}$ & $\begin{array}{l}(95-119) \\
(17-28)\end{array}$ \\
\hline Total & 374 & $100 \cdot 0$ & $129 \cdot 7$ & $(117-143)$ \\
\hline
\end{tabular}

CDMS, clinically definite multiple sclerosis;

LSDMS, laboratory supported definite multiple sclerosis; CPMS, clinically probable multiple sclerosis;

CPMS, clinically probable multiple sclerosis;
LSPMS, laboratory supported probable multiple sclerosis;

MS ? classification, definite or probable multiple sclerosis (unverified)

MS ? classification, definite or probable multiple sclerosis (unverified);
Suspected MS, "possible" multiple sclerosis but not "definite" or "probable" according to the Poser criteria. 
Table 3 Comparison of prevalence rates of multiple sclerosis using the Poser criteria: Cambridge, Southampton, ${ }^{6}$ South East Wales ${ }^{5}$

\begin{tabular}{|c|c|c|c|c|c|c|c|c|c|c|c|c|}
\hline & \multicolumn{4}{|c|}{$\begin{array}{l}\text { Cambridge } H A \\
\text { Prevalence }\end{array}$} & \multicolumn{4}{|c|}{$\begin{array}{l}\text { Southampton/South West Hants } H A \\
\text { Prevalence }\end{array}$} & \multicolumn{4}{|c|}{$\begin{array}{l}\text { South East Wales } \\
\text { Prevalence }\end{array}$} \\
\hline & No & $(\%)$ & $110^{5}$ & $95 \% C I$ & No & $(\%)$ & $110^{5}$ & $95 \% C I$ & No & $(\%)$ & $110^{5}$ & $95 \% C I$ \\
\hline \multicolumn{13}{|l|}{ Poser category } \\
\hline CDMS & 256 & $(79 \cdot 5)$ & $88 \cdot 8$ & $(78-100)$ & 318 & $(80 \cdot 5)$ & $76 \cdot 3$ & $(68-92)$ & 298 & $(78 \cdot 2)$ & $79 \cdot 0$ & $(71-89)$ \\
\hline LSDMS & 10 & $(3 \cdot 1)$ & $3 \cdot 5$ & $(1-6)$ & 14 & $(3 \cdot 5)$ & $3 \cdot 4$ & $(2-6)$ & 20 & $(5 \cdot 2)$ & $5 \cdot 3$ & $(3-8)$ \\
\hline CPMS & 51 & $(15 \cdot 9)$ & $17 \cdot 7$ & $(13-23)$ & 47 & $(11.9)$ & $11 \cdot 3$ & $(8-15)$ & 41 & $(10 \cdot 8)$ & $10 \cdot 9$ & $(8-15)$ \\
\hline LSPMS & 1 & $(0 \cdot 3)$ & $0 \cdot 3$ & $(0-1)$ & 0 & & & & 1 & $(0 \cdot 3)$ & $0 \cdot 3$ & $(0-2)$ \\
\hline MS? classification & 4 & $(1 \cdot 2)$ & $1 \cdot 4$ & $(0-3)$ & 16 & $(4 \cdot 1)$ & $3 \cdot 8$ & $(2-6)$ & 21 & $(5 \cdot 5)$ & $5 \cdot 6$ & $(3-9)$ \\
\hline Total in Poser & 322 & $(100)$ & $111 \cdot 6$ & $(99-124)$ & 395 & $(100)$ & $94 \cdot 7$ & $(88-107)$ & 381 & $(100)$ & $101 \cdot 1$ & $(92-112)$ \\
\hline Suspected MS & 52 & & $18 \cdot 0$ & $(13-23)$ & 16 & & $3 \cdot 8$ & $(2-6)$ & 60 & & 15.9 & $(12-21)$ \\
\hline Total all cases & 374 & & & & 411 & & & & 441 & & & \\
\hline
\end{tabular}

CDMS, clinically definite multiple sclerosis; LSDMS, laboratory supported definite multiple sclerosis; CPMS, clinically probable multiple sclerosis; LSPMS, laboratory supported probable multiple sclerosis; MS ? classification, definite or probable multiple sclerosis (unverified); Suspected MS, "possible" multiple sclerosis but not "definite" or "probable" according to the Poser criteria.

Table 4 Prevalence of multiple sclerosis in the Cambridge Health Authority per 100,000 by age and sex

\begin{tabular}{|c|c|c|c|c|c|c|c|c|c|}
\hline \multirow{2}{*}{$\begin{array}{l}\text { Age Group } \\
\text { (years) }\end{array}$} & \multicolumn{3}{|c|}{ Male } & \multicolumn{3}{|c|}{ Female } & \multicolumn{3}{|c|}{ Total } \\
\hline & No & Rate $/ 10^{5}$ & $(95 \% C I)$ & No & Rate/10 & $(95 \% C I)$ & No & Rate $/ 10^{5}$ & $(95 \% C I)$ \\
\hline $0-14$ & 0 & 0 & & 0 & 0 & & 0 & 0 & \\
\hline $15-24$ & 0 & 0 & & 3 & 14 & $(0-30)$ & 3 & 7 & $(0-14)$ \\
\hline $25-34$ & 9 & 40 & $(14-67)$ & 34 & 154 & $(102-205)$ & 43 & 97 & $(68-126)$ \\
\hline $35-44$ & 35 & 187 & $(125-249)$ & 95 & 527 & $(421-633)$ & 130 & 354 & (293-414) \\
\hline $45-54$ & 21 & 132 & $(76-189)$ & 52 & 333 & $(243-423)$ & 73 & 232 & (179-285) \\
\hline $55-64$ & 21 & 145 & $(83-206)$ & 37 & 238 & $(162-315)$ & 58 & 193 & $(143-243)$ \\
\hline $65-74$ & 17 & 143 & $(75-211)$ & 34 & 236 & $(157-315)$ & 51 & 194 & $(141-247)$ \\
\hline$>75$ & 2 & 32 & $(0-76)$ & 10 & 89 & $(34-144)$ & 12 & 68 & $(30-107)$ \\
\hline Unknown & 1 & & & 3 & & & 4 & & \\
\hline Total & 106 & 75 & $(60-89)$ & 268 & 184 & $(162-206)$ & 374 & 130 & $(117-143)$ \\
\hline
\end{tabular}

Table 5 Comparison of surveys from Cambridge, Southampton, ${ }^{6}$ Sutton, ${ }^{4}$ Aberdeen $^{316}$ and South Glamorgan ${ }^{5}$

\begin{tabular}{lllllll}
\hline & $\begin{array}{l}\text { Cambridge } \\
1990\end{array}$ & $\begin{array}{l}\text { Southampton } \\
1987\end{array}$ & $\begin{array}{l}\text { Sutton } \\
1985\end{array}$ & $\begin{array}{l}\text { Aberdeen } \\
1970\end{array}$ & $\begin{array}{l}\text { Aberdeen } \\
1980\end{array}$ & $\begin{array}{l}\text { S. Glamorgan } \\
1985\end{array}$ \\
\hline Population & 288410 & 411000 & 169600 & 440176 & 471000 & 376718 \\
Number of cases & 374 & 411 & 195 & 557 & 839 & 441 \\
Prevalence (/100 000) & $130(117-143)$ & $99(89-109)$ & $115(99-131)$ & $127(117-138)$ & $178(166-190)$ & $117(106-128)$ \\
Probable (/100 000) & 107 & 92 & 104 & 105 & 144 & 84 \\
Mean age & $49 \cdot 2$ & $48 \cdot 6$ & $49 \cdot 0$ & $48 \cdot 2$ & $45 \cdot 1$ & $48 \cdot 7$ \\
Age onset & $29 \cdot 6$ & $32 \cdot 6$ & $34 \cdot 1$ & $34 \cdot 2$ & $34 \cdot 5$ & $32 \cdot 2$ \\
Mean duration & $19 \cdot 2$ & $15 \cdot 7$ & $15 \cdot 4$ & $14 \cdot 4$ & $14 \cdot 8$ & $16 \cdot 5$ \\
Incidence $\left(/ 10^{5 / y e a r)}\right.$ & $5 \cdot 9(1989-91)$ & $4 \cdot 7(1976-82)$ & $5(1974-84)$ & $5 \cdot 3(1959-73)$ & $7 \cdot 2(1977-80)$ & $5 \cdot 4(1947-84)$ \\
Sex ratio F: M & $2 \cdot 5$ & $2 \cdot 1$ & $2 \cdot 3$ & $1 \cdot 6$ & 1.9 & \\
SPR & $121(108-133)$ & $115(104-127)$ & $129(111-147)$ & $153(140-166)$ & $221(184-261)$ & $139(126-150)$ \\
\hline
\end{tabular}

SPR, standardised prevalence ratio using Northern Ireland $1961=100$ (see text).
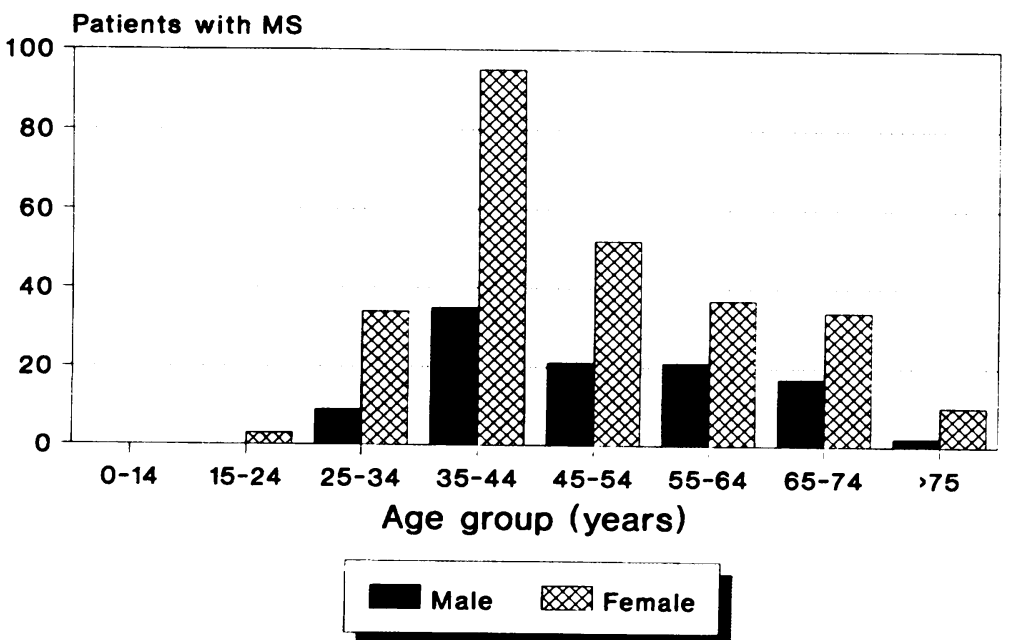

Figure 1 Age distribution by sex. prevalence ratio of 121 (95\% CI 108-133) for the study area, calculated using the method of Williams and McKeran, ${ }^{4}$ this shows the result that would have been obtained in the present study if the age/sex population structure in the Cambridge Health District was the same as the population structure of the population surveyed in the 1961 survey of Northern Ireland. ${ }^{14}$ This calculation permits comparison of prevalence in areas of different age structure, and the result is similar to that obtained in recent surveys from Southampton, South Glamorgan and Sutton; but lower that the most recent figure for Aberdeen. ${ }^{16}$

A prospective study of the incidence of MS in the Cambridge Health Authority was started during the present prevalence survey. Between 1 July 1990 and 1 September 1991, 76 new diagnoses of MS were made by Cambridge based neurologists. Most of the patients ( 56 $(74 \%)$ ) were not resident in the area under study, which reflects established work patterns for the Cambridge neurology unit. Twenty new cases $(26 \%)$ were resident in the study area, 
giving a crude estimate for the current local incidence of MS of 5.9 per 100000 per year, (95\% CI 3.9-10.0). None of the prevalent patients with suspected MS was known to have developed probable or definite forms of the disease during the prospective period, but the conversion rate has not yet been formally investigated.

\section{Discussion}

This study is the first population-based study of MS available for eastern England and only the fourth study of multiple sclerosis in the southern part of the UK to be carried out during the past thirty years, the others having been performed in Sutton (South London), South Glamorgan ${ }^{5}$ and the Southampton/ South West Hampshire areas. ${ }^{6}$ The epidemiological methods used in this study are comparable with those applied to the populations of South Glamorgan and Southampton, and the results need to be examined together with the findings of these other surveys. The crude prevalence rate of $130 / 10^{5}$ obtained for Cambridge is higher than figures for Sutton, South Glamorgan and Southampton, $\left(115 / 10^{5}, 117 / 10^{5}\right.$ and $99 / 10^{5}$ respectively). However, only the difference in prevalence

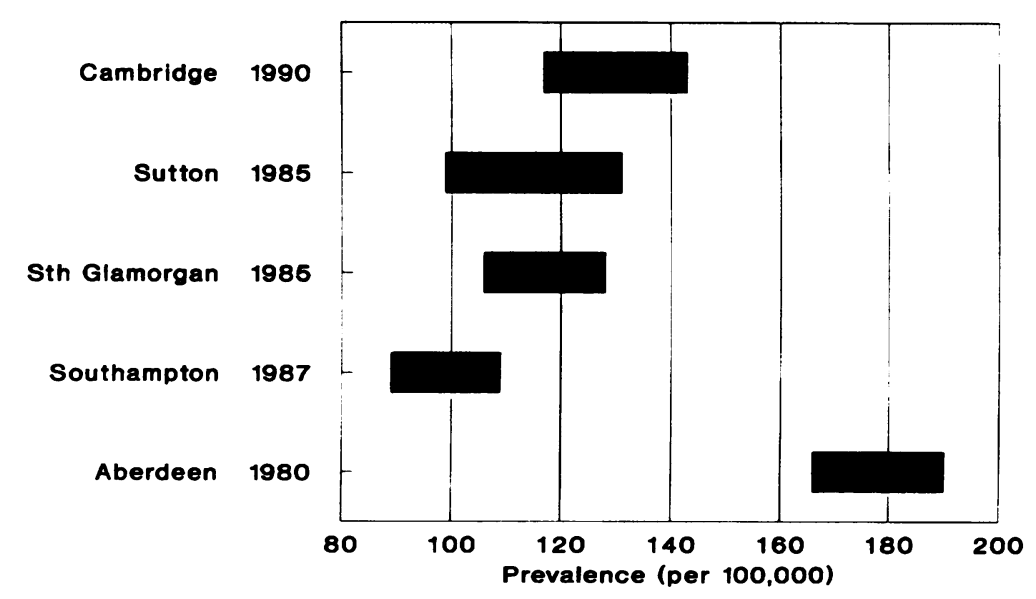

Figure 2 MS prevalence: $95 \%$ confidence intervals.

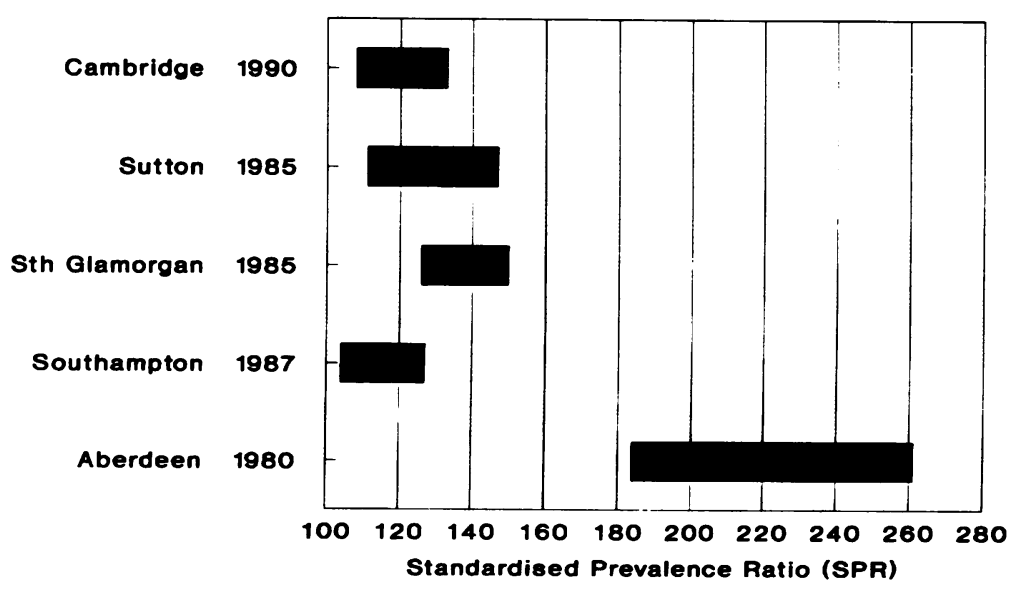

Figure 3 SPR: 95\% confidence intervals. between the present study and Southampton achieves statistical significance, $\left(x^{2}=14 \cdot 8, p<\right.$ 0.001 ), and the $95 \%$ confidence intervals for Cambridge $\left(117-143 / 10^{5}\right)$ show considerable overlap with those obtained in the Sutton and South Glamorgan surveys $\left(99-131 / 10^{5}\right.$ and $106-128 / 10^{5}$ respectively; fig 2 ). Differences in population structure are important in comparing studies since the age and sex structure of the surveyed populations is not necessarily identical; MS affects females more than males and is more prevalent in younger adults than the elderly population. The calculation of a standardised prevalence ratio (SPR) removes these differences, and estimates figures for disease prevalence which would have been obtained if the age and sex structure of each area were identical. The SPR obtained in the present survey $(121,95 \%$ CI 108-133) is similar to those for Sutton, South Glamorgan and Southampton surveys, (129, 139 and 115 respectively; fig 3 ).

Characteristics of the patients with MS identified in each of the recent studies are also similar. There is a close correlation between the proportion of MS patients falling into each of the Poser diagnostic categories in Cambridge, Southampton and South Glamorgan (table 3). Mean age at prevalence, age of onset and disease duration are also similar between the three populations (table 5).

Summation of the prevalence results from the Sutton, South Glamorgan, Southampton and Cambridge surveys gives an estimated prevalence figure for the southern UK of $114 / 10^{5}$, and the $95 \%$ confidence intervals narrow to $108-119 / 10^{5}$. This form of crude meta-analysis assumes homogeneous distribution of the disease as well as identical population age and sex structures between areas, and since these are known not to be valid, a result derived in this way can only be interpreted with extreme caution. However, taken with the three other studies the present results offer enough evidence to assume a prevalence figure considerably higher than the estimate of 50-70 per 100000 which is still quoted in the literature. ${ }^{17}$

The question of whether a latitudinal gradient exists for MS in the UK remains unresolved. The most recent figures obtained for the prevalence of MS in Scotland have been consistently higher than the best data available for England and Wales. ${ }^{16}$ Scotland has received intensive and repeated epidemiological scrutiny, ${ }^{38916}$ and the most recent data are the product of sequential surveys. In contrast, data from England and Wales result from initial surveys performed in a single area. It has been argued that resurveying a given area greatly increases case ascertainment, and that comparison between studies should be restricted to data from first surveys. ${ }^{4}$ The prevalence figure for Aberdeen increased from 127/100 000 in $1970^{3}$ to $178 / 100000$ in $1980,{ }^{16}$ but a reassessment of the 1985 South Glamorgan data in 1988 did not show a marked change in results ${ }^{18}$ and it may be the case that initial surveys are now achieving more complete case ascertainment due to improved methodology. 
Both the crude prevalence figure and the standardised prevalence ratio obtained in this study are significantly lower than the most recent Scottish figures, and this supports the argument that the distribution of MS in the UK has a significant north-south gradient, possibly resulting from a genetic bias. ${ }^{51920} \mathrm{An}$ analysis of mortality statistics for the past thirty years has suggested that there is a decline in the mortality differential between Scotland and England with a consequent dissipation of a previous latitudinal prevalence gradient. ${ }^{21}$ The present findings suggest that a north-south gradient persists.

Roberts $e t a l^{6}$ have argued that there is a need for a multi-centre comparative assessment of the prevalence of MS in the UK, and cite the recent Australian study as a model survey in which all centres used identical methods and diagnostic criteria. ${ }^{22}{ }^{23}$ We support this suggestion, which would provide optimal epidemiological data. Although the logistics of such an exercise are considerable, the need for precise methodology and diagnostic criteria should not deter individual investigators from undertaking local prevalence surveys.

This study was funded by the Multiple Sclerosis Society of Great Britain and Northern Ireland. We are grateful to the other Great Britain and Northern Ireland. We are grateful to the other the MRC Biostatistics Unit in Cambridge for statistical the M

1 Sutherland JM. Observations on the prevalence of multiple sclerosis in Northern Scotland Brain 1956;79:635-54.

2 Pozkanzer DC, Schapira K, Miller H. Epidemiology of multiple sclerosis in the counties of Northumberland and multiple sclerosis in the counties of Northumberland and
Durham. $₹$ Neurol Neurosurg Psychiatry 1963;26:368-76.

3 Shepherd DI, Downie AW. Prevalence of multiple sclerosis Shepherd DI, Downie AW. Prevalence of multiple
in north-east Scotland. BMF 1978;ii:314-6.

in north-east Scotland. BMF 1978;ii:314-6.
Williams ES, McKeran RO. Prevalence of multiple sclerosis Williams ES, McKeran RO. Prevalence of multiple scle
in a south London borough. $B M \mathcal{F}$ 1986;293:237-9.

5 Swingler RJ, Compston DAS. The prevalence of multiple sclerosis in South East Wales. $\mathcal{f}$ Neurol Neurosurg Psy- chiatry 1988;51:1520-4

6 Roberts MHW, Martin JP, McLellan DL, Michaelis SAMcI, Spackman AJ. The prevalence of multiple sclerosis in the Southampton and South West Hampshire Health Authority. $f$ Neurol Neurosurg Psychiatry 1990;53:55-9.

7 Lockyer MJ. Prevalence of multiple sclerosis in five rural Suffolk practices. BMF 1991;303:347-8.

8 Shepherd DI, Downie AW. A further prevalence study of multiple sclerosis in north-east Scotland. 7 Neurol Neurosurg Psychiatry 1980;43:310-5.

9 Downie AW. The chief scientist reports ... Multiple sclerosis in north-east Scotland. Health Bull (Edinb) 1984; 42/3:1561-6.

10 Cambridgeshire County Council Research Group. Population Forecasts 1989-2001 (Cambridgeshire). Cambridge: Cambridgeshire County Council, 1991.

11 Office of Population Censuses and Surveys. Census 1981. County Report Cambridgeshire pts 1 and 2. London: HMSO, 1982.

12 Poser CM, Paty DW, Scheinberg L, et al. New diagnostic criteria for multiple sclerosis: guidelines for research protocols. Ann Neurol 1983;13:227-31.

13 Allison RS, Millar JHD. Prevalence and familial incidence of disseminated sclerosis (A report to the Northern Ireland Hospitals Authority on the results of a three-year survey). Prevalence of disseminated sclerosis in Northern Ireland. Ulster Med ๆ 1954;23(suppl No 2):5-27.

14 Millar JHD. Multiple sclerosis in Northern Ireland. In Clifford Rose F, ed. Clinical neuroepidemiology. Tunbridge Wells: Pitman Medical, 1980:222-7.

15 Martyn CN, Osmond C. The prevalence of multiple sclerosis in south east Wales (Letter). $\mathcal{Y}$ Neurol Neurosurg Psychiatry 1989;52:1017.

16 Phadke JG, Downie AW. Epidemiology of multiple sclerosis in the north east (Grampian Region) of Scotland -an update. F Epi Comm Health 1987;41:5-13.

17 Elian M, Dean G. Multiple sclerosis among United Kingdom born children of immigrants from the West Indies. 7 Neurol Neurosurg Psychiatry 1987.50:327-32.

18 Hennessy A, Swingler RJ, Compston DAS. The incidence and mortality of multiple sclerosis in South East Wales. $\mathcal{f}$ Neurol Neurosurg Psychiatry 1989;52:1085-9.

19 Swingler RJ, Compston DAS. The distribution of multiple sclerosis in the United Kingdom. $f$ Neurol Neurosurg sclerosis in the United Kingd

20 Swingler RJ, Kirk PF, Darke C, Compston DAS. HLA and multiple sclerosis in south east Wales. $\mathcal{F}$ Neurol Neurosurg Psychiatry 1987;50:1153-5.

21 Williams ES, Jones DR, McKeran RO. Mortality rates from multiple sclerosis: geographical and temporal variation revisited. I Neurol Neurosurg Psychiatry 1991;54:104-9.

22 Hammond SR, McLeod JG, Millingen KS, et al. The epidemiology of multiple sclerosis in three Australian cities: Perth, Newcastle and Hobart. Brain 1987;111: $1-25$.

23 Hammond SR, English D, de Wytt C, et al. The clinical profile of multiple sclerosis in Australia: a comparison between medium- and high-frequency prevalence zones. Neurology 1988;38:980-6. 